\title{
On the AD 1815 Tambora eruption and the matter of misplaced tree rings
}

\author{
Scott St. George ${ }^{1}$ and Kevin J. Anchukaitis ${ }^{2}$
}

\section{A debate about volcanic eruptions and missing tree rings has spurred new research into the integrity of tree-ring dating and the impact of exceptionally cold summers on arctic and alpine forests.}

On 10 April 1815, Mount Tambora erupted, sending "three columns of flame" into the sky above Sumbawa, Indonesia (Stothers 1984). By the time the volcano returned to slumber, $50 \mathrm{~km}^{3}$ of rock had been vaporized, 71,000 people in Indonesia had died, and roughly $60 \mathrm{Mt}$ of sulfur had been injected into the stratosphere (Oppenheimer 2003). In terms of total atmospheric loading, Tambora ranks as the third-largest volcanic event of the last 1500 years, eclipsed only by the 1257 Samalas and 1453 Kuwae eruptions (Gao et al. 2008).

The brilliant red, purple and orange sunsets seen in London during the following summer and autumn (Stothers 1984) were among the first signs the effects of this eruption would extend far beyond the Dutch East Indies. For many Europeans and North Americans in 1816, aberrant weather became the norm. Snow fell across Quebec, Maine, and New York state in June, mid-summer frosts extended as far south as New Jersey, and incessant cold and rain prevailed across England and central Europe (Oppenheimer 2003). The unseasonable weather, shortened growing season, and widespread crop failures led to 1816 being memorialized as the "Year Without a Summer".

Exactly how much cooling occurred in 1816 and how much was due to Tambora remains a point of contention nearly two centuries later. Limited instrumental measurements suggest Northern Hemisphere temperatures dipped 0.7 to $0.8^{\circ} \mathrm{C}$ in 1816 (Stothers, 1984), but few weather stations were active at this time and most were in Europe (D'Arrigo et al. 2013). Both proxy reconstructions and climate simulations show strong cold anomalies in 1816, but some model experiments (Mann et al. 2012) produce more cooling than supported by proxies.

\section{The Year Without a Ring?}

The mismatch between proxy reconstructions and climate simulations could be due to one of several potential causes, including estimates of Tambora's stratospheric aerosol loadings being too high or models exhibiting an excessively strong thermodynamic response to explosive volcanism.
But one study proposed that proxies are the root cause of this disagreement and specifically called to question the ability of tree rings to track exceptionally cold years. Mann et al. (2012) argued the Year Without a Summer was so frigid that trees near their thermal limit in arctic and alpine forests remained dormant throughout the entire growing season and, as a result, did not form a ring for that year. If that were so, the ring for 1816 would be missing, paleotemperature estimates for 1816 would be incorrectly based on the 1815 ring, and prior to the Tambora eruption, tree-ring records would have a one-year chronological error.

The "missing 1816" scenario was initially criticized for its implementation of a treering-growth model and a lack of empirical evidence for dating errors in tree-ring chronologies (Anchukaitis et al. 2012). More recently, this debate has provided the motivation for new research investigating how trees react to extreme cold and testing whether extraterrestrial influences on radiocarbon production can be used to corroborate or refute the current tree-ring timeline. In this Highlight article, we report on some of this latest work and discuss its implications for our understanding of Tambora and the sensitivity of the Earth's climate system to major volcanic eruptions.

\section{Hunting the invisible}

Every year, trees in boreal and temperate forests produce a new growth ring. But acute environmental stress, such as moisture deficits, wildfire, or insect attacks, can sometimes cause a portion of the tree's vascular cambium, the source of new wood, to remain dormant throughout the entire growing season. In those cases, the new growth ring will be discontinuous along the stem, present in some positions (usually near the crown) and absent at others (usually near the ground). The possibility that some years may be missing is one of the main reasons why tree-ring dating is accomplished through pattern-matching and not ring counting.

Perhaps because identifying missing rings is a routine step in chronology building, most tree-ring studies do not report how often they occur or where and when they are common. To address this shortcoming, St. George et al. (2013) produced a synthesis of locally absent rings across the Northern Hemisphere during the last millennium drawing upon 2,359 tree ring-width records. Absent rings did occur frequently across the American Southwest during severe droughts, but were extremely rare in tree-ring records from high-latitude or high-elevation sites. Based on their hemispheric survey, St. George et al. (2013) established that, in order for the "missing 1816" scenario to be valid, a wide swath of the boreal forest would have needed to exhibit a reaction to environmental stress that has never been observed anywhere at any time during the last millennium.

\section{Validating the tree-ring calendar} But what if the 1816 rings were actually missing? Esper et al. (2012) conducted an experiment by modifying several tree-ring density records from Northern Scandinavia and the European Alps so that 1816 was entirely absent, the rings originally placed at 1816 were re-assigned to 1815 , and the dates of all prior rings were shifted earlier by one year. The altered tree-ring sequences showed no correspondence with either temperature measurements from early weather stations or a five-century long summer temperature reconstruction for central Europe derived from documentary evidence. They concluded that, unless the tree-ring series, instrumental climate data, and historical reconstructions all share precisely the same dating error, the original tree-ring chronologies must be correct.

D'Arrigo et al (2013) also explored the consequences of making revisions to the tree-ring timeline. Density records from Labrador, Canada and the Scottish Cairngorms are excellent surrogates for summer temperature, but inserting a missing ring at 1816 destroys the correlation between local weather observations made in the late 1700 s and early 1800 s and the tree-ring series. They also pointed out that the lowest density value in the entire Labrador record occurred in 1816. If we assume that year was missing, this extreme 


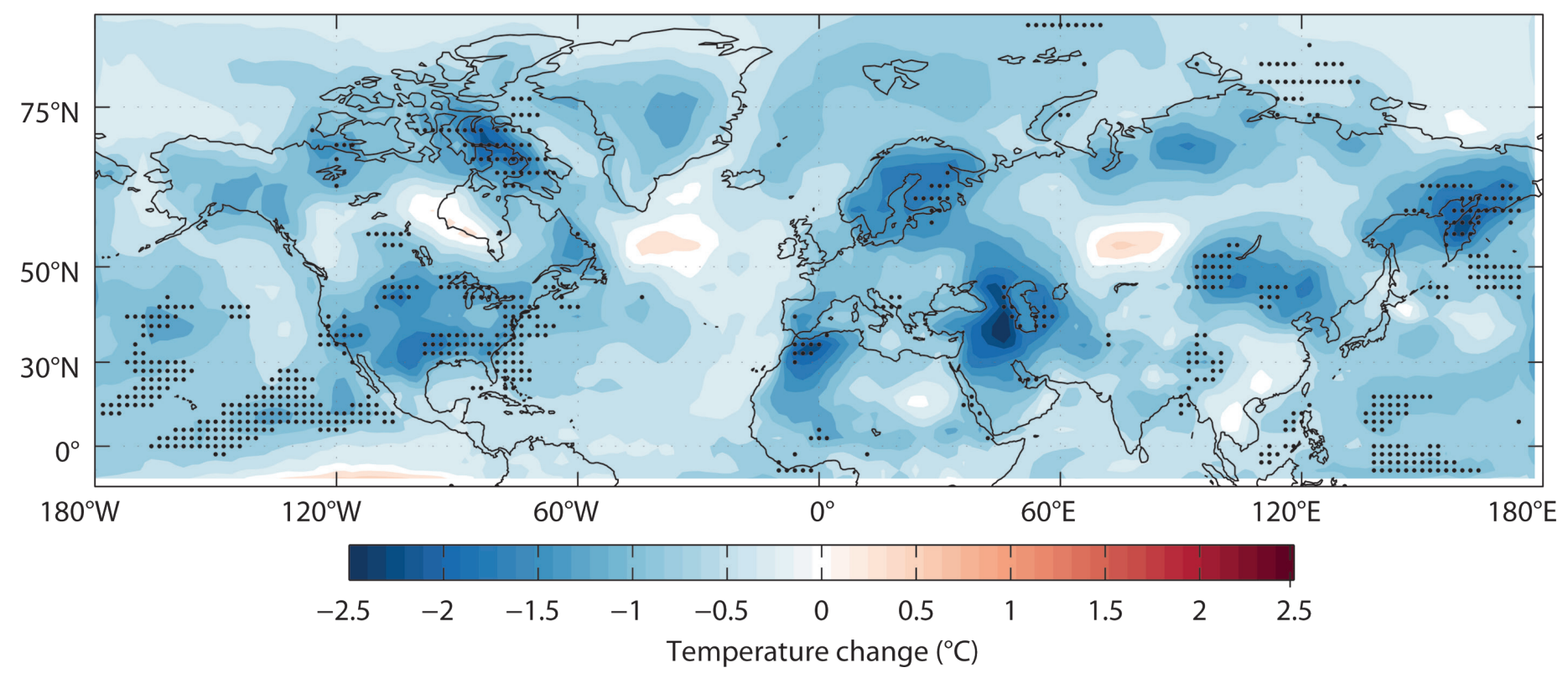

Figure 1: Simulated cooling during the northern summer (JJA) of AD 1816, as estimated by the Coupled Model Intercomparison Project Phase 5 (Taylor et al. 2012). The shading represents the multi-model mean temperature difference between the northern summer of 1816 and 1815 , and stippling illustrates locations where at least seven of eight model ensemble members agree on the sign of the temperature change.

value would be re-assigned to 1815 , which was not a particularly cold summer.

The other novel line of evidence affirming the tree-ring calendar emanates from an extraterrestrial source. Miyake et al. (2012) announced that tree rings from two Japanese cedars exhibited a rapid increase in radiocarbon content from $A D$ 774 to 775 , and argued this enrichment was evidence of a short-lived global surge in atmospheric ${ }^{14} \mathrm{C}$ production provoked by a cosmic-ray event. The AD 774-775 spike in radiocarbon content has subsequently been detected in Germany (Usoskin et al. 2013), Siberia and California (Jull et al. 2014), the Austrian Alps (Büntgen et al. 2014), and New Zealand (Güttler et al. 2015). Other researchers have argued this radiocarbon excursion was due to a different type of extraterrestrial event, such as an exceptional solar flare, a cometary impact on the sun, or a gamma-ray burst. But regardless of its origin, the fact that the same ${ }^{14} \mathrm{C}$ signature is discernible in chronologies from both temperature- and moisture-limited settings confirms the accuracy of tree-ring dating over (at least) the last twelve centuries.

\section{More tests for the trees?}

There are still other ways to verify the fidelity of tree-ring dates prior to the Tambora eruption. Rutherford and Mann (2014) singled out specific tree-ring records they believed to have chronological errors caused by volcanic cooling: Tornetraesk (northern Sweden), Taymir (far-northern Siberia), and the Gulf of Alaska (United States). For those regions or records hypothesized to have been most strongly affected by the Tambora eruption, it may be worthwhile to verify their dating by testing for the presence of the radiocarbon excursion in their AD 775 rings. Dissecting complete trees along their stem, sampling trees that would have been juvenile in 1816 , or tracing the
1816 ring from cold, marginal forests to more hospitable environments downslope or towards the forest interior, could also help confirm the integrity of the tree-ring timeline.

But at this point, it is questionable what will be gained by additional efforts expended to refute a hypothesis that 1816 is missing from any portion of the global tree-ring network. Trees growing in high-latitude and high-elevation forests are adapted to cool summers and short growing seasons, and almost never skip rings under any circumstances. Forcing a missing ring at 1816 causes the well-established association between summer temperature and tree-ring width and density at thermally-limited sites to vanish. The ubiquity of the $8^{\text {th }}$ century ${ }^{14} \mathrm{C}$ marker demonstrates the Year Without a Summer was not a year without a ring. It also refutes the proposition that the larger Samalas or Kuwae eruptions caused widespread shutdowns at treeline forests in the Alps, California or northern Siberia.

There are many reasons why proxies and models might disagree on the magnitude of cooling caused by Tambora. All models show the Northern Hemisphere was cold during the summer of AD 1816 (Fig. 1) but, at a regional scale, they disagree on the pattern and magnitude of cooling and in some cases run counter to instrumental temperature measurements (for example, in Scandinavia). It is also true that trees are not solely influenced by one aspect of climate but instead integrate the influence of several environmental factors prior to and during the growing season. Because volcanic aerosols enhance the forward scattering of incoming solar radiation, major eruptions might actually cause trees to photosynthesize more efficiently, offsetting the negative effects of shortterm cooling. But whatever the source of the apparent differences between proxies and models, an overwhelming body of evidence shows the Tambora eruption did not interrupt the yearly calendar kept by trees around the globe.

\section{AFFILIATIONS}

'Department of Geography, Environment and Society, University of Minnesota, Minneapolis, USA

${ }^{2}$ School of Geography and Development \& Laboratory of Tree Ring Research, Tucson, USA

\section{CONTACT}

Scott St. George: stgeorge@umn.edu

\section{REFERENCES}

Anchukaitis KJ et al (2012) Nat Geosci 5: 836-837 Büntgen U et al (2014) Nat Clim Chang 4: 404-405 D'Arrigo RD et al. (2013) J Geophys Res Atmos 118 $9000-9010$

Esper J et al. (2012) Dendrochronologia 31: 216-222

Gao C et al. (2008) J Geophys Res Atmos 113, do:10.1029/2008JD010239

Güttler D et al. (2015) Earth Planet Sci Lett 411: 290-297

Jull AJT et al. (2014) Geophys Res Lett 41, doi: 10.1002/2014GL059874

Mann ME et al. (2012) Nat Geosci 5: 202-205

Miyake F et al. (2012) Nature 486: 240-242

Oppenheimer C (2003) Prog Phys Geog 27: 230-259

Rutherford S, Mann ME (2014) Nat Clim Change 4: 648-649

St. George S et al. (2013) Geophys Res Lett 40, doi: $10.1002 / g r l .50743$

Stothers RB (1984) Science 224: 1191-1198

Taylor KE et al. (2012) Bull Am Meteorol Soc 93: 485-498

Usoskin IG et al. (2013) Astronom Astrophys 552, doi: 10.1051/0004-6361/201321080 